\title{
Building the Resilient Indonesia's Education in Pandemic Era : Lessons from Taiwan and the United States
}

\author{
Lalu Suprawesta ${ }^{1}$, Amja Manullang ${ }^{2}$, Mohammad Ainul Maruf 3* $^{\text {* }}$ \\ ${ }^{1}$ Graduate Institute of Injury Prevention and Control, College of Public Health, Taipei \\ Medical University, Taipei, Taiwan \\ ${ }^{1}$ Department of Sport and Health Education, Faculty of Sport Science and Public Health, \\ Universitas Pendidikan Mandalika, West Nusa Tenggara, Indonesia \\ ${ }^{2}$ International Ph.D. Program in Medicine, College of Medicine, Taipei Medical University, \\ Taipei, Taiwan \\ ${ }^{3}$ Faculty of Public Health, University of Muhammadiyah Jakarta \\ ${ }^{3}$ Global Health and Health Security, College of Public Health, Taipei Medical University, \\ Taipei, Taiwan \\ *Corresponding Author. Email: arvin.ainul@umj.ac.id
}

\begin{abstract}
The aim of the study is to analyze the measures from Taiwan and the United States that responded to the Covid-19 in high education institutions. The method that was conducted in this study is qualitative with a narrative review as a data technique. Data collected from reviewed the relevant literature that meets inclusion criteria as the primary object. The descriptive qualitative analysis technique was used. The result of this study concludes that some measures from Taiwan and United States can be matched according to the characteristic in Indonesia. These two countries provide several lessons in tackling the Covid-19 problem in the education sector by preventing the transmission since the beginning, taking mitigation steps to reduce the speed of the spread of the virus, applying clear regulations and guidelines in various fields of life including education, and have a sense of sensitivity to relaxed and tightened of regulations.
\end{abstract}

\section{Article History}

Received: 23-08-2021

Revised: 24-10-2021

Accepted: 22-11-2021

Published: 11-12-2021

\author{
Key Words: \\ Education, \\ Higher Education \\ Institutions, \\ Lessons Learned, \\ Covid-19.
}

How to Cite: Suprawesta, L., Manullang, A., \& Maruf, M. (2021). Building the Resilient Indonesia's Education in Pandemic Era: Lessons from Taiwan and the United States. Jurnal Kependidikan: Jurnal Hasil Penelitian dan Kajian Kepustakaan di Bidang Pendidikan, Pengajaran dan Pembelajaran, 7(4), 778-784. doi:https://doi.org/10.33394/jk.v7i4.4100

https://doi.org/10.33394/jk.v7i4.4100

This is an open-access article under the CC-BY-SA License.

\section{Introduction}

Society is now more aware of the field of public health and the role of public health professionals in addressing the pandemic. Public health has long been known to play a key role in population health (Brisolara \& Smith, 2020), especially in prevention strategies. The significance of this expertise allowed some countries in Asia, such as Taiwan, South Korea, and Singapore, to fight the coronavirus more successfully (Bauchner \& Sharfstein, 2020). At the time of this update, the Covid-19 pandemic continues to have a terrible impact on lives worldwide. As of August 2021, there have been 200.566 .338 cases and 4.624.642 deaths in the world (Worlemeter,2021). In Indonesia, 3.440.396 confirmed cases had occurred, resulting in 95.723 deaths. There are 9.9 percent of cases with $0.5 \%$ of deaths among schoolaged children (6-18 years old), and $25.1 \%$ of cases with $2.8 \%$ of deaths among those aged 1930 years old (Satuan Petugas Penanganan Covid-19, 2021).

As health and safety concerns remain unclear, there is considerable pressure on schools to find a way to educate every student in all segments while causing the least amount of disruption (Hale et al., 2021). So, a quick response from higher education leaders is 
urgently needed for effective mitigation strategies. According to the CDC, higher education institutions, together with state and local health officials, may determine whether and how these considerations are applied while adapting to the unique needs and circumstances. The realization of the project must be guided by the practicable, acceptable, and adaptable needs of each school member and the community. In addition, educators can play a significant role in preventing in-school transmission through physical distancing and mask use.

In response to the outbreak of Covid-19 in Indonesia, Minister of Education and Culture Nadiem Makarim issued Circular Letter Number 4 of 2020 on March 24, 2020. This established letter informed Indonesian educators of emergency-specific policies regarding the implementation of educational practices during the spread of the Covid-19. Through this circular, the Minister of Education and Culture sets forth the Minister's 2020 Policy for Home-Based Learning. In November 2020, Directorate General of Higher Education (DIKTI) released a circular letter Number 6 of 2020 informing that universities students starting in January 2021 can be held face-to-face and online (hybrid learning). Students' exams, like the national exams and equivalency exams, were all abolished in February 2021, according to circular letter number 1 of 2021 issued by the Minister of Education.

In Taiwan, the Ministry of Education created general guidelines for college campuses to ensure the safety of students and faculty. There were detailed guidelines for the creation of a task force at each university, as well as school-based risk screening that is based on the student's travel history, job, contacts, and clusters. The following safety measures were also outlined: measures on self-management of health, and a process for reporting suspected cases. And policies on school closings and make-up classes were also made (Cheng, Wang, Shen, \& Chang, 2020).

A variety of mitigation measures were implemented in some states in the United States in August 2020, including increased physical spacing in classrooms, the requirement for students to wear face masks in class and other common areas, as well as adjustments to dining to reduce overcrowding (Walke, Honein, \& Redfield, 2020). Lastly, all classes were moved to an online format, which has proven to be extremely successful. During the period of online classes, the university focused on facilitating access to testing, expanding contact tracing, isolation, and quarantine operations, and implementing screening tests for asymptomatic people, as well as enhancing the data systems to support these measures (Fox, Bailey, Seamon, \& Miranda, 2021). This narrative review article discusses how education institutions in Taiwan and the United States responded to the Covid-19 pandemic then we discussed the kind of measures done in both contries that can be followed in Indonesia.

\section{Research Method}

The method that was conducted in this study is qualitative with a narrative review as a data technique. Data collected from reviewed the relevant literature that meets inclusion criteria as the primary object. We searched for information and news regarding higher education's response to the Covid-19 pandemic in Taiwan and the US from Google Scholar, PubMed databases, and ministry of education websites. The sources were limited to English and Indonesian languages by the time frame between January 2020 and August 2021. The search terms used were "Taiwan", "US", "higher education response", "college", "university campus", "Covid-19 and students", "Covid-19 and higher education", and "Covid-19 response". The data were analyzed in descriptively qualitative. 


\section{Results and Discussion \\ Lesson from Taiwan}

In general, compare to Indonesia, Taiwan have taken some measures that affect the resilience in education program in pandemic era. The lessons from Taiwan including 1) Developing the robust national public healthcare network, 2) Taking fast response before the first cases reported, 3) Developing the guidelines in preventing pandemic spread by involving all sectors and practicing in various conditions that may be impacted by pandemic, 4) Constructing an integrated educational program for pandemic condition, and 5) Taking some measures that sufficient to prevent and contain viral spread by all colleges and universities meber depending on the incidence and prevalence.

Taiwan has procedures in place to prevent any future epidemics, based on lessons learned during the 2003 SARS outbreak. A robust national public health network, complete universal healthcare for all people, a thriving medical research and pharmaceutical sector, and improved infection control methods are all strengths of the country. Since the epidemic, Taiwan has started a long-term investment in expanded capacity at the Centers for Disease Control (CDC), hospitals, and infectious disease laboratories. The Ministry of Health and Welfare (MOHW) directed the Taiwan CDC, which is responsible for communicable disease prevention, surveillance, investigation, and control, has made significant efforts to improve its disease control capacity by strengthening the regulatory power of the Communicable Disease Control Act (Ministry of Justice, 2020).

The Taiwanese government's response to Covid-19 is to take steps of speed, vigilance, and decisiveness. When the first reports of a new virus in China emerged on December 31, 2019, Taiwan began screening arrivals from Wuhan, imposing home quarantine on individuals with fever and possible respiratory symptoms. The Taiwan CDC created the Central Epidemic Command Center (CECC) on January 20, 2020, in response to the rising severity of the epidemic in China and neighboring regions, with the minister of the MOHW as the main commander and high-rank officials from other ministries as the core members. The leadership of the CECC and the Taiwan CDC are critical in combating the Covid-19 epidemic. Personal hygiene policies, preventative actions in schools and businesses, the identification and isolation of suspected and proven cases, the expropriation of mask makers, and mask rationing all necessitate efficient public-private engagement and partnerships. (Control, 2020; Han, Chiou, McKee, \& Legido-Quigley, 2020; Yeh \& Cheng, 2020).

The Taiwanese CDC released a set of guidelines outlining preventive actions to be taken by various actors in various situations. The Ministry of Education has declared campus closures for both public and private institutions. The CECC stated on March 20, 2020 that all instructors, students, and staff in high school and lower will be prohibited from going abroad. Many colleges and universities have also freely implemented online classrooms and teleconferencing. Schools and other educational institutions have returned to normal as the pandemic has decreased since late May. The Taiwanese Ministry of Education created broad rules for college campuses to ensure the safety of students and employees [Ministry of Education, 2020]. The guide describes the formation of working groups at each university and the risk assessment at the school based on travel history, occupation, contacts and groups; self-management of sanitary and quarantine measures, general sanitation measures (including the use of masks indoors); ventilation and sanitation principles, School assembly regulations, suspected case reporting procedures and policy formulation.

There are some consequences and impacts of the pandemic for college students in Taiwan. The construction of an integrated educational program for health professionals, 
lifestyle modifications and college students' health condition, and the learning efficacy of physical classroom and online learning for dentistry education during the Covid-19 pandemic are among the latest research. Health professionals' workers may increase their learning opportunities through the hospital wide-courses, continued placement of test questions and learning files on digital learning platforms, placement of journal highlights in cloud folders and using the digital learning platform on mobile phones accessible outside the hospital (Chiu et al., 2021). The lifestyles change of college students were found by decreased frequency of daily activities and had fewer opportunities for socialization and interaction with peers and faculty under the new procedures created by the pandemic of Covid-19 [Chen et.al., 2019]. Dental education may adopt the combination of physical classroom and online course as the future trend since the dental students tended to have online class learning was better than physical classroom but more feel convenience to have physical classroom examination than online examination (Yu-Fong Chang, Wang, Lin, Cheng, \& Chiang, 2021).

Taiwan have successfully done some measures such as active campus-based screening and access control; school-based travel, occupant, contact, cluster (TOCC) screening and quarantine protocol; student and faculty quarantine as needed; mobilization of administrative and health center staff; regulation of dorms and cafeteria; and reinforcement of personal hygiene, environmental sanitation, and indoor air ventilation. These measures will be sufficient to prevent and contain viral spread on campus depending on the incidence and prevalence of disease in a school's location (Cheng et al., 2020).

\section{Lesson from the United States}

Covid-19 was first detected in the US in January and February 2020 among travelers from Hubei Province, China, and their family contacts (Jernigan \& CDC Covid Response Team, 2020). Since then, the US CDC has taken several measures to prevent local transmission from occurring. However, there were certain factors that make the spread of the virus difficult to avoid such as the continued viral importation from other countries, the participation at mass and gathering events, the introduction of the virus into potentially amplification-prone facilities, and the obstacles in virus detention, and the other cryptic transmission (Schuchat \& CDC COVID Response Team, 2020). Until now, there were at least 4 waves of Covid-19 transmission in the US (Wilson, 2021).

Even in the US, Covid-19 pandemic has had a detrimental impact on higher education, including dental education, medical education, and other field of education (Ahmed, Allaf, \& Elghazaly, 2020; Ferrel \& Ryan, 2020; Iyer, Aziz, \& Ojcius, 2020; Rose, 2020). The reopening of college and universities in the fall of 2020 presented new problems and risk for transmission on campuses and neighboring communities. The risk of severe health outcomes might be lower among college students. However, the faculty, university staff and family of college students at home and in the communities may be at a significantly higher risk of severe illness and death if infected (Walke et al., 2020).

The US CDC anticipated existing risks and problems by issuing guidelines with the tagline "plan, prepare, and response" for colleges and universities. Those guidelines include the guiding principles and mitigation strategies for reopening the institution, when to quarantine on campus, testing for Covid-19, case investigation and contact tracing, guidance for shared or congregate housing, guidance of using transportation, and also how to cope with stress for student, administrators, faculty and staff (Center for Disease Control and Prevention, 2020). The guidelines are also accompanied by easy-to-understand posters and videos which can be accessed on their websites. 
In dealing with the potential decline in the number of public health workers (ASPH Policy Brief, 2008; Leider, Coronado, Beck, \& Harper, 2018), several public health schools and programs had contributed to the public health response to Covid 19 by providing applied practice experiences for students (Burns, Strickland, \& Horney, 2021; Council on Education for Public Health, 2020). They keep running the fieldwork initiative in the midst of challenges such as travel restrictions, university closure, working on-site restrictions, and others (Centers for Disease Control Prevention, 2021). This showed that public health students can take part in efforts to mitigate the devastating effects of the pandemic.

Distance learning education also plays an important role during this pandemic in the US. Fortunately, the US has a long history of developing distance learning (Cook \& Dupras, 2004). There are several key players from the US who develop Massive Open Online Courses (MOOCs), such as edX, Pluralsight, Udacity, Udemy, Simplilearn, Edmodo, LinkedIn, NovoEd, Skillshare, and Khan Academy. It puts the US as the leading MOOC platform on this planet. Moreover, up to $80 \%$ of colleges in the US offer their courses online (Wotto, 2020). However, some argued that distance learning cannot simply replace traditional education especially if schools and students do not prepare it properly (Christakis, 2020).

\section{Conclusion}

Indonesia has its own characteristics that cannot simply be matched with the situation in Taiwan and the United States. However, there are several lessons that can be learned from the two countries in tackling the COVID-19 problem in the education sector. First, it is very important to prevent transmission from the beginning. Second, when local transmission cannot be overcome, it is necessary to take mitigation steps to reduce the speed of the spread of the virus. Third, there needs to be clear regulations and guidelines to be applied in various fields of life, including education. Fourth, those regulations need to be disseminated and accompanied by law enforcement. Fifth, there needs to be a sense of sensitivity to know when regulations can be relaxed and when they can be tightened.

When planning to reopen a school or campus, the considerations used must be based on a rational approach. Indeed, young people are not categorized as vulnerable groups. However, their mobility can endanger vulnerable groups. Moreover, in Indonesia, usually, young people live with their families at home. Under one roof there can be three generations, grandparents, parents, and children. Even in implementing distance learning from home, it is necessary to pay attention to whether the student has supporting devices, such as laptops, and internet access for instance, in their homes. The gap between rural and urban areas, between the rich and the poor, also needs special attention, both from the central and local governments.

\section{Recommendation}

This pandemic should be a point where improvements are carried out on an ongoing basis to avoid the impact of the next pandemic in the future. Educational institutions themselves in which there are teachers/faculty members, students and education managers, need to see this as an opportunity to improve the quality of education as a whole. As the main actors of the education sector, they must be able to adapt to changes and implement innovations that are appropriate to the context in which they are located. It is also possible to see learning from other regions or other countries while still paying attention to local wisdom. 


\section{References}

Ahmed, H., Allaf, M., \& Elghazaly, H. (2020). COVID-19 and medical education. The Lancet Infectious Diseases, 20(7), 777-778.

ASPH Policy Brief. (2008). Confronting the Public Health Workforce Crisis. Retrieved August 23, 2021, from ASPH http://www.nevadapublichealthfoundation.org/wpcontent/themes/nphf/userfiles/WorkforceShortage2010Final.pdf

Bauchner, H., \& Sharfstein, J. (2020). A Bold Response to the COVID-19 Pandemic: Medical Students, National Service, and Public Health. Jama, 323(18), 1790-1791. doi:10.1001/jama.2020.6166

Brisolara, K. F., \& Smith, D. G. (2020). Preparing Students for a More Public Health-Aware Market in Response to COVID-19. Prev Chronic Dis, 17, E56. doi:10.5888/pcd17.200251

Burns, K. F., Strickland, C. J., \& Horney, J. A. (2021). Public health student response to COVID-19. Journal of Community Health, 46(2), 298-303.

Center for Disease Control and Prevention. (2020). College \& Universities: Plan, Prepare, and Respond. Retrieved August 23, 2021, from The US CDC https://www.cdc.gov/coronavirus/2019-ncov/community/collegesuniversities/index.html

Centers for Disease Control Prevention. (2021). Considerations for institutions of higher education.

Cheng, S. Y., Wang, C. J., Shen, A. C., \& Chang, S. C. (2020). How to Safely Reopen Colleges and Universities During COVID-19: Experiences From Taiwan. Ann Intern Med, 173(8), 638-641. doi:10.7326/m20-2927

Chiu, T. F., Chu, D., Huang, S. J., Chang, M., Liu, Y., \& Lee, J. J. (2021). Facing the Coronavirus Pandemic: An Integrated Continuing Education Program in Taiwan. Int $J$ Environ Res Public Health, 18(5). doi:10.3390/ijerph18052417

Christakis, D. A. (2020). School reopening-the pandemic issue that is not getting its due. JAMA pediatrics, 174(10), 928-928.

Control, T. C. f. D. (2020). Prevention and Control of COVID-19 in Taiwan. Retrieved from https://www.cdc.gov.tw/En/Category/Page/0vq8rsAob_9HCi5GQ5jH1Q

Cook, D. A., \& Dupras, D. M. (2004). A practical guide to developing effective web-based learning. Journal of general internal medicine, 19(6), 698-707.

Council on Education for Public Health. (2020). COVID-19 Related Updates: Practice Experience. Retrieved August 23, 2021, from Council on Education for Public Health https://ceph.org/covid19/

Ferrel, M. N., \& Ryan, J. J. (2020). The impact of COVID-19 on medical education. Cureus, 12(3).

Fox, M. D., Bailey, D. C., Seamon, M. D., \& Miranda, M. L. (2021). Response to a COVID19 Outbreak on a University Campus - Indiana, August 2020. MMWR Morb Mortal Wkly Rep, 70(4), 118-122. doi:10.15585/mmwr.mm7004a3

Government of Taiwan, 2021. Communicable Disease Control Act. Ministry of Justice Laws \& Regulations Database of The Republic of China. Retrieved August 02, 2021 from https://law.moj.gov.tw/ENG/LawClass/LawAll.aspx?pcode=L0050001

Hale, T., Angrist, N., Goldszmidt, R., Kira, B., Petherick, A., Phillips, T., . . . Tatlow, H. (2021). A global panel database of pandemic policies (Oxford COVID-19 Government Response Tracker). Nat Hum Behav, 5(4), 529-538. doi:10.1038/s41562021-01079-8 
Han, E., Chiou, S. T., McKee, M., \& Legido-Quigley, H. (2020). The resilience of Taiwan's health system to address the COVID-19 pandemic. EClinicalMedicine, 24, 100437. doi:10.1016/j.eclinm.2020.100437

Iyer, P., Aziz, K., \& Ojcius, D. M. (2020). Impact of COVID 19 on dental education in the United States. Journal of dental education, 84(6), 718-722.

Jernigan, D. B., \& CDC COVID Response Team. (2020). Update: public health response to the coronavirus disease 2019 outbreak-United States, February 24, 2020. Morbidity and mortality weekly report, 69(8), 216.

Leider, J. P., Coronado, F., Beck, A. J., \& Harper, E. (2018). Reconciling supply and demand for state and local public health staff in an era of retiring baby boomers. American journal of preventive medicine, 54(3), 334-340.

Ministry of Education, 2020. Guideline on severe special infectious pneumonia prevention on campus. $\quad$ Retrieved August $\quad 05, \quad 2021$ from www.edu.tw/News_Content.aspx? $\mathrm{n}=0217161130 \mathrm{~F} 0 \mathrm{~B} 192 \& s m s=\mathrm{DD} 4 \mathrm{E} 27 \mathrm{~A} 7858227 \mathrm{~F}$ F\&s=E75749E5FBC8D181

Rose, S. (2020). Medical student education in the time of COVID-19. Jama, 323(21), 21312132.

Schuchat, A., \& CDC COVID Response Team. (2020). Public health response to the initiation and spread of pandemic COVID-19 in the United States, February 24-April 21, 2020. Morbidity and mortality weekly Report, 69(18), 551.

Taiwan Centers for Disease Control, 2021. COVID-19 Coronavirus disease 2019 (COVID19). Guidelines. Retrieved June 20, 2021 from https://www.cdc.gov.tw/En/Category/MPage/G8mN-MHF7A1t5xfRMduTQQ

Taiwan Centers for Disease Control, 2020. Prevention and Control of COVID-19 in Taiwan. Retrieved August 03,2021 from https://www.cdc.gov.tw/En/Category/Page/0vq8rsAob_9HCi5GQ5jH1Q

Walke, H. T., Honein, M. A., \& Redfield, R. R. (2020). Preventing and responding to COVID-19 on college campuses. Jama, 324(17), 1727-1728.

Wilson, C. (2021). A Fourth Wave of COVID-19 Is Brewing in the U.S. Is There Enough Time to Stop It? Retrieved August 23, 2021, from Time.com https://time.com/6081407/covid-19-fourth-wave/

Wotto, M. (2020). The future high education distance learning in Canada, the United States, and France: Insights from before COVID-19 secondary data analysis. Journal of Educational Technology Systems, 49(2), 262-281.

Yeh, M. J., \& Cheng, Y. (2020). Policies Tackling the COVID-19 Pandemic: A Sociopolitical Perspective from Taiwan. Health Secur, 18(6), 427-434. doi:10.1089/hs.2020.0095

Yu-Fong Chang, J., Wang, L. H., Lin, T. C., Cheng, F. C., \& Chiang, C. P. (2021). Comparison of learning effectiveness between physical classroom and online learning for dental education during the COVID-19 pandemic. J Dent Sci, 16(4), 1281-1289. doi:10.1016/j.jds.2021.07.016 